\title{
Fetal haemoglobin and early manifestations of homozygous sickle cell disease
}

\author{
K Bailey, J S Morris, P Thomas, G R Serjeant
}

\begin{abstract}
The relevance of fetal haemoglobin (HbF) concentration to the development of early clinical manifestations of homozygous sickle (SS) disease has been investigated by examining the time to first occurrence and the proportional hazard of these complications in three groups of the $\mathrm{HbF}$ distribution at age 5 years. HbF was significantly related to dactylitis, painful crises, acute chest syndrome, and acute splenic sequestration. The relationship suggested that a critically low $\mathrm{HbF}$ concentration increased the risk, little difference in risk occurring between the medium and high HbF groups. The abdominal painful crisis and hypersplenism were not related to $\mathrm{HbF}$ concentration suggesting that the degree of sickling may not be important in their genesis. Parental education on acute splenic sequestration should be focused on children with HbF concentrations in the lowest part of the $\mathrm{HbF}$ distribution for age.
\end{abstract}

One factor contributing to the highly variable natural history of homozygous sickle cell (SS) disease appears to be the concentration of fetal haemoglobin $(\mathrm{HbF})$. High concentrations are generally associated with mild clinical courses in patients of African origin ${ }^{1}$ and also characterise the relatively benign disease observed in the eastern province of Saudi Arabia ${ }^{2}$ and central India. ${ }^{3}$ However, some patients with high $\mathrm{HbF}$ values have severe manifestations and others with low values may be mildly affected, casting doubt on the clinical relevance of $\mathrm{HbF}$ concentrations. ${ }^{4}$ A Jamaican study of SS disease in the first two years of a neonatally defined cohort has reported that low concentrations of $\mathrm{HbF}$ were significantly related to the early appearance of splenomegaly, and a greater incidence of dactylitis and acute splenic sequestration. ${ }^{5}$ Observations in this study have now been extended to a median age of 12 years and to other clinical complications.

\section{Patients and methods}

Patients participated in a cohort study of sickle cell disease based on a cord blood screening programme at the main government maternity hospital (Victoria Jubilee Hospital) in Kingston, Jamaica. Between mid-1973 and late 1981, a total of 100000 infants were screened with the detection of 314 cases of SS disease. Of these, 308 were located and recruited to cohort clinics operated by the staff of Medical Research Council Laboratories at the University Hospital of the West Indies. Routine appointments were given at intervals of one month up to six months, two months to one year, and three months thereafter and children were encouraged to attend at any time if sick. The study group was confined to 223 subjects (119 male, 104 female) who had survived beyond 4.5 years and in whom adequate $\mathrm{HbF}$ estimations and clinical data were available. Of the 85 subjects excluded, 41 had died or emigrated before 4.5 years, and 44 had insufficient $\mathrm{HbF}$ values or clinical data. The latter group included patients with more than one year of default in whom it was assumed that recall would be inaccurate. Patients were. aged $4 \cdot 7-17 \cdot 4$ years at the time of the study and median follow up was 12 years.

The diagnosis of SS disease was based on criteria previously described. ${ }^{6}$ Blood samples were taken by venepuncture at yearly intervals on the child's birthdate or when clinically indicated. Standard haematological methods were used. $\mathrm{HbF}$ was determined by an alkali denaturation method after making standard haemolysates. ${ }^{7}$

The relationship between $\mathrm{HbF}$ concentration and clinical events was investigated by dividing patients into three groups on the basis of $\mathrm{HbF}$ value at age 5 years. $\mathrm{HbF}$ values were available within six months of this target age in 223 subjects and the distribution was derived separately for the two sexes and arbitrarily divided into three groups of approximately equal size representing the low, medium, and high portions of this distribution at age 5 years (table 1). To ascertain that the $\mathrm{HbF}$ group at age 5 years was characteristic of an individual subject, the assignment to $\mathrm{HbF}$ group was compared in a subset of patients with $\mathrm{HbF}$ concentrations at both 5 and 10 years, and showed that the same HbF group assignments occurred in $65 / 83(78 \%)$ males and in $61 / 83$ (73\%) females. All other subjects except one

Table 1 Concentrations of $\mathrm{HbF}(\%)$ defining $\mathrm{HbF}$ groups in both sexes at 5 and 10 years of age

\begin{tabular}{|c|c|c|c|c|}
\hline \multirow[t]{2}{*}{$H b F$ group } & \multicolumn{2}{|l|}{ Males } & \multicolumn{2}{|l|}{ Females } \\
\hline & $\begin{array}{l}\text { No of } \\
\text { patients }\end{array}$ & $\begin{array}{l}\text { Defining } \\
\text { concentration }\end{array}$ & $\begin{array}{l}\text { No of } \\
\text { patients }\end{array}$ & $\begin{array}{l}\text { Defining } \\
\text { concentration }\end{array}$ \\
\hline $\begin{array}{l}\text { Age } 5 \text { years: } \\
\text { Low } \\
\text { Medium } \\
\text { High }\end{array}$ & $\begin{array}{l}40 \\
40 \\
39\end{array}$ & $\begin{array}{l}\leqslant 4 \cdot 8 \\
4 \cdot 9-9 \cdot 7 \\
\geqslant 9 \cdot 8\end{array}$ & $\begin{array}{l}36 \\
34 \\
34\end{array}$ & $\begin{array}{l}\leqslant 6 \cdot 1 \\
6 \cdot 2-10 \cdot 3 \\
\geqslant 10 \cdot 4\end{array}$ \\
\hline Total & 119 & & 104 & \\
\hline $\begin{array}{l}\text { Age } 10 \text { years: } \\
\text { Low } \\
\text { Medium } \\
\text { High }\end{array}$ & $\begin{array}{l}26 \\
28 \\
29\end{array}$ & $\begin{array}{l}\leqslant 2 \cdot 4 \\
2 \cdot 5-6 \cdot 3 \\
\geqslant 6.3\end{array}$ & $\begin{array}{l}30 \\
27 \\
26\end{array}$ & $\begin{array}{l}\leqslant 3 \cdot 8 \\
3 \cdot 9-7 \cdot 4 \\
\geqslant 7 \cdot 5\end{array}$ \\
\hline Total & 83 & & 83 & \\
\hline
\end{tabular}

Council Research

(Jamaica),

University of the West Indies,

Jamaica, WI.

Accepted 1 October 1991 
deviated only to an adjacent $\mathrm{HbF}$ group. A similar analysis has also confirmed a close relationship between $\mathrm{HbF}$ group assignments at six months and two years. ${ }^{5}$

Clinical events were defined as follows. Dactylitis referred to an acute, painful, nonpitting swelling of the hands, feet, fingers, or toes with no evidence of infection. The painful crisis was defined as an episode of bone pain at two or more sites of sufficient severity to interfere with function, two sites being specified to avoid confusion with localised avascular necrosis of bone. The abdominal painful crisis referred to localised or generalised abdominal pain and tenderness, but without the characteristics of other medical or surgical conditions. Acute chest syndrome was associated with pleuritic pain, fever, cough, respiratory distress, and clinical or radiological signs of pulmonary infiltration. Acute splenic sequestration was defined according to the expanded definition of Topley et al involving acute splenic enlargement, ${ }^{8}$ a fall in haemoglobin concentration of at least $20 \mathrm{~g} / \mathrm{l}$, and evidence of increased bone marrow activity. Hypersplenism applied to sustained splenic enlargement of $4 \mathrm{~cm}$ or more associated with haemoglobin concentrations below $65 \mathrm{~g} / \mathrm{l}$, and platelet counts below $260 \times$ $10^{9} / 1$ on at least two occasions six months or more apart.

The incidence of these clinical events in the two sexes in the different $\mathrm{HbF}$ groups was initially examined by the survival curve method, which allows for changes in the population at risk from death, default, or emigration, and the relative risks compared by the log rank test. Significance of the association between clinical events and $\mathrm{HbF}$ group was assessed by the $\chi^{2}$ test for trend. All data were used in the survival analysis, although the figures presented were truncated to 10 years, to avoid the misleading effect on the survival curves of few remaining older patients.

As certain sex differences in the relationship between $\mathrm{HbF}$ and clinical features emerged from survival curve analysis and as the $\mathrm{HbF}$ distribution differed in the two sexes, these relationships were further investigated by proportional hazards regression using generalised linear interactive modelling (GLIM) and the method described by Aitkin et al. ${ }^{9}$ This method has the advantage over conventional survival analysis of simultaneous adjustment for a number of potential confounding factors. For this analysis the entire study population was divided into three equal sized groups on the basis of $\mathrm{HbF}$ concentration at age 5 years: group I, $\mathrm{HbF}<5 \cdot 4 \%$; group II, $\mathrm{HbF} 5 \cdot 4-9 \cdot 7 \%$; group III, $\mathrm{HbF} \geqslant 9 \cdot 8 \%$. The factors entered into the model were $\mathrm{HbF}$, sex, and the $\mathrm{HbF}$-sex interaction.

\section{Results}

The relationships between clinical events and HbF group as assessed by survival curve analysis are shown graphically in figs $1-4$ and their significance summarised in table 2 .

Acute chest syndrome had occurred in 186 patients. Age at first occurrence was significantly related to $\mathrm{HbF}$ in both sexes and did not differ between the sexes. The survival curve data (fig 1) suggested that the group with low $\mathrm{HbF}$ was particularly prone with less difference between the medium and high $\mathrm{HbF}$ groups.

Dactylitis occurred in 113 patients. The trend with $\mathrm{HbF}$ was highly significant in males (fig 2A) but although the females in the low $\mathrm{HbF}$

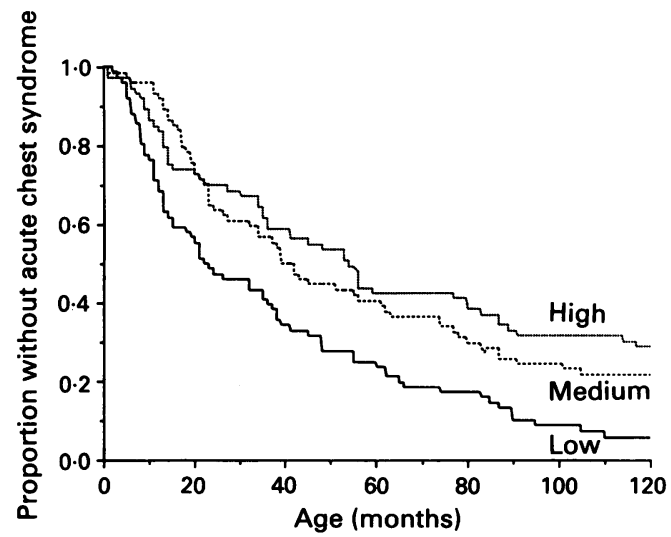
Figure 1 Survival curve analysis of the first occurrence of
the acute chest syndrome in subjects of both sexes according to $\mathrm{HbF}$ groups.

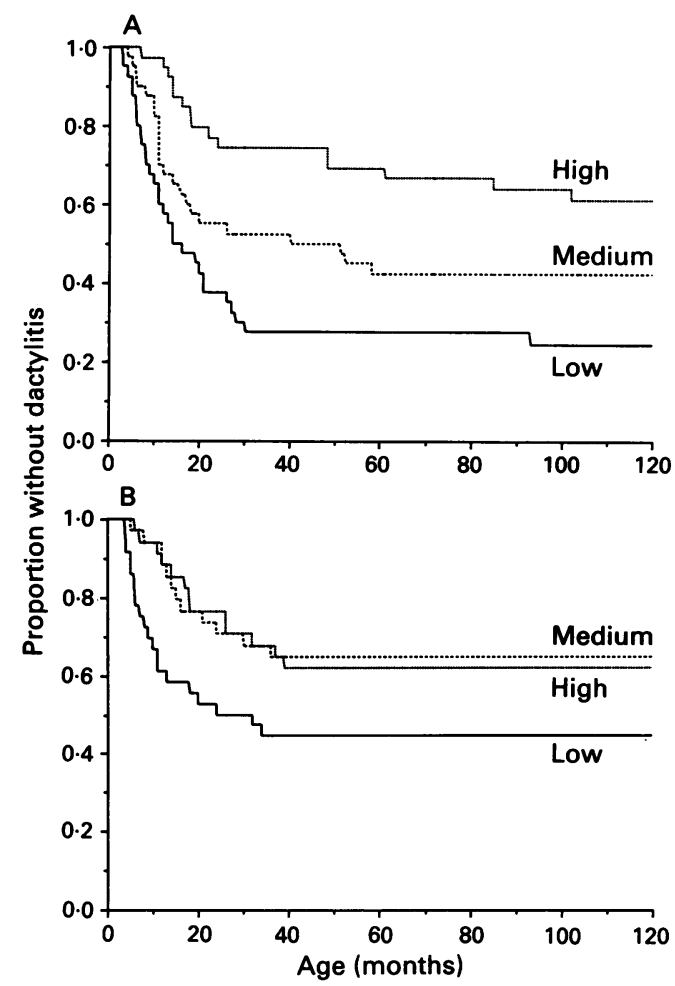

Figure 2 Survival curve analysis of the first occurrence of dactylitis according to $\mathrm{HbF}$ group in $(A)$ males and (B) females.

Table 2 Relationship of clinical events with $\mathrm{HbF}$ group assessed by $\chi^{2}$ test for trend on survival curve analysis

\begin{tabular}{|c|c|c|c|c|}
\hline \multirow[t]{2}{*}{ Event } & \multicolumn{2}{|l|}{ Males } & \multicolumn{2}{|c|}{ Females } \\
\hline & $\overline{x^{2}}$ & p Value & $\overline{x^{2}}$ & p Value \\
\hline $\begin{array}{l}\text { Acute chest syndrome } \\
\text { Dactylitis } \\
\text { Painful crisis } \\
\text { Acute splenic sequestration } \\
\text { Hypersplenism } \\
\text { Abdominal painful crisis }\end{array}$ & $\begin{array}{r}8 \cdot 07 \\
14 \cdot 54 \\
5 \cdot 69 \\
14 \cdot 13 \\
0 \cdot 31 \\
0 \cdot 83\end{array}$ & $\begin{array}{r}0.005 \\
<0.001 \\
0.017 \\
<0.001 \\
0.580 \\
0.363\end{array}$ & $\begin{array}{l}6 \cdot 30 \\
3 \cdot 45 \\
0 \cdot 58 \\
2 \cdot 78 \\
0 \cdot 03 \\
1 \cdot 41\end{array}$ & $\begin{array}{l}0.012 \\
0.063 \\
0.445 \\
0.095 \\
0.869 \\
0.236\end{array}$ \\
\hline
\end{tabular}


group were affected earlier and more frequently (fig 2B), the trend was not significant in females.

Painful crises occurred in 157 patients. The relationship with $\mathrm{HbF}$ group was significant in males (fig 3A) but not in females (fig 3B).

Acute splenic sequestration occurred in 88 patients. The relationship with $\mathrm{HbF}$ concentration was significant in males (fig 4A) but not in females (fig 4B). As expected, most episodes occurred before 3 years of age and of those episodes occurring after 3 years, all but one were in the high $\mathrm{HbF}$ group.

Hypersplenism occurred in 32 patients, and there was no relationship with $\mathrm{HbF}$ concentration in either sex. Abdominal painful crisis occurred in 123 patients, and was not influenced by $\mathrm{HbF}$ group in either sex.

The apparent sex difference in the significance of $\mathrm{HbF}$ with some complications could have resulted from the greater proportion of males with low $\mathrm{HbF}$ values if a critically low concentration of $\mathrm{HbF}$ were an important determinant. The results of proportional hazard analysis support this as expressing the risk of complications in HbF groups II and III in relation to group I (table 3) show significantly lower risk in

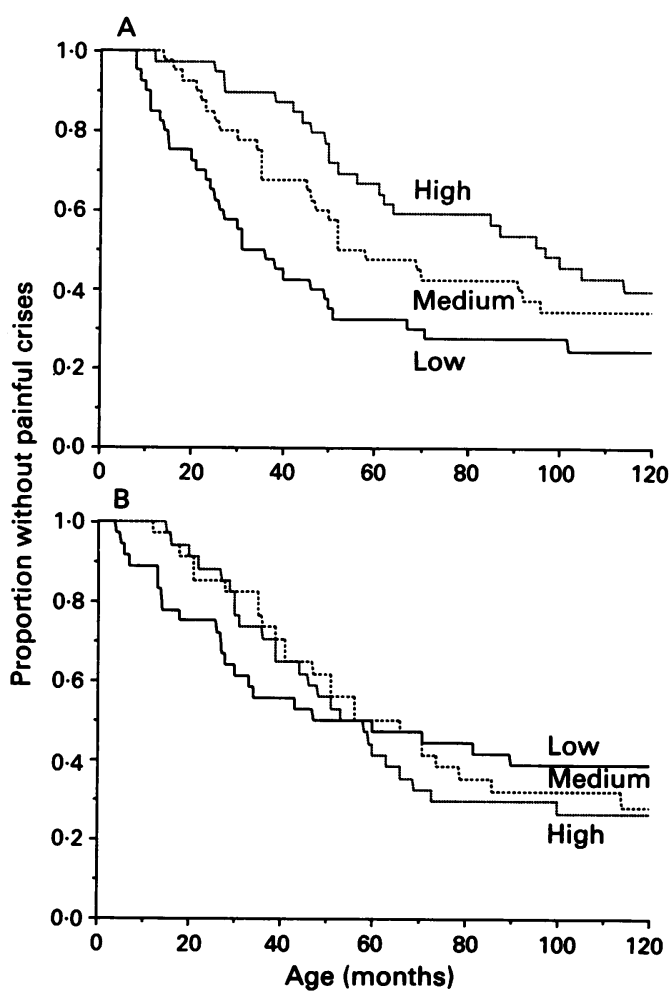

Figure 3 Survival curve analysis of the first occurrence of painful crisis according to $H b F$ group in $(A)$ males and (B) females.

Table 3 Hazard rates for clinical events according to $\mathrm{HbF}$ grouping expressed relative to group I (95\% confidence intervals)

\begin{tabular}{lll}
\hline Event & $\begin{array}{l}\text { Group } I I \\
(H b F \text { 5.4-9.7\%) }\end{array}$ & $\begin{array}{l}\text { Group III } \\
(H b F \geqslant 9.8 \%)\end{array}$ \\
\hline Acute chest syndrome & $0.55(0.39$ to 0.78$)$ & $0.48(0.34$ to 0.69$)$ \\
Dactylitis & $0.39(0.25$ to 0.61$)$ & $0.32(0.20$ to 0.52$)$ \\
Painful crisis & $0.59(0.40$ to 0.88$)$ & $0.69(0.47$ to 1.01$)$ \\
Acute splenic sequestration & $0.63(0.39$ to 1.02$)$ & $0.31(0.18$ to 0.55$)$ \\
Hypersplenism & $0.62(0.25$ to 1.53$)$ & $0.83(0.36$ to 1.88$)$ \\
Abdominal painful crisis & $0.96(0.62$ to 1.49$)$ & $0.96(0.62$ to 1.50$)$ \\
\hline
\end{tabular}

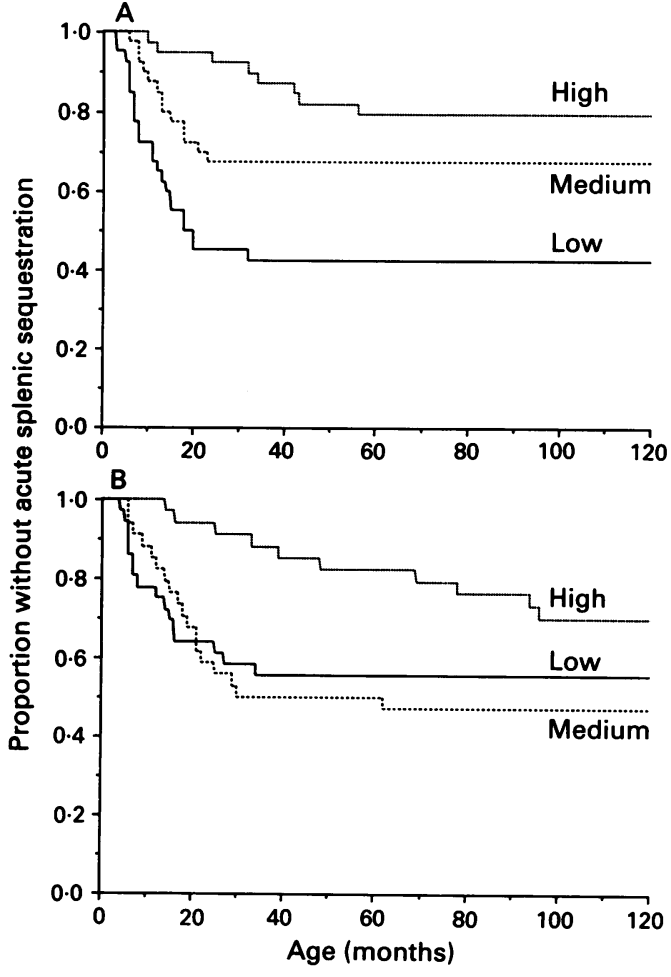

Figure 4 Survival curve analysis of the first occurrence of acute splenic sequestration according to $H b F$ group in $(A)$ males and $(B)$ females.

the higher HbF groups for dactylitis, painful crisis, acute chest syndrome, and acute splenic sequestration. Furthermore, adding sex to the model did not improve the fit indicating that these relationships were true independent of sex. Proportional hazard analysis also confirmed the lack of any relationship between $\mathrm{HbF}$ and abdominal painful crisis or hypersplenism.

\section{Discussion}

Previous observations in the cohort study showed that patients with low concentrations of $\mathrm{HbF}$ were more prone to develop dactylitis and acute splenic sequestration. ${ }^{5}$ The present study has shown that low $\mathrm{HbF}$ is also a risk factor for painful crisis and acute chest syndrome. The relevance of $\mathrm{HbF}$ to clinical features appears to conflict with observations by Powars et al in Los Angeles who initially failed to find a relationship between $\mathrm{HbF}$ concentration and any clinical event except stroke, ${ }^{4}$ although they later postulated that a critical concentration of $\mathrm{HbF}$ may protect against certain complications of the disease. ${ }^{10}$

Several differences in the Jamaican and American studies may have contributed to the apparently different conclusions. The present study was confined to survival curve analysis, which assesses only the timing of the first event and not the frequency of subsequent events within individuals. The Jamaican study has used clearly defined end points, which have been consistently applied from the onset of the cohort study. Furthermore the Jamaican study has used only prospectively recorded data in contrast to the American study that used inevitably less accurate retrospective data. 
Finally the Jamaican population was a representative sample in contrast to the American group who were predominantly symptomatically acquired. For these reasons it seems justified to conclude that the Jamaican observations are less prone to bias.

Children in the lowest third of the $\mathrm{HbF}$ distribution at age 5 years were more prone to the acute chest syndrome, dactylitis, painful crises, and acute splenic sequestration. As there was a close correlation between $\mathrm{HbF}$ groupings at six months and two years ${ }^{5}$ and between age 5 and 10 years, it seems reasonable to assume that the position within an $\mathrm{HbF}$ distribution is characteristic for an individual child. Placement within the $\mathrm{HbF}$ distribution may therefore be of prognostic importance for these complications and prophylactic or education programmes may be devised accordingly. For example education on parental detection of acute splenic sequestration ${ }^{11}$ may be focused in high risk groups.

The apparent conflict between data from the survival curve analysis that showed some sex differences and that from proportional hazard analysis that did not, could be explained if a $\mathrm{HbF}$ value below a critical concentration was necessary as a risk factor for these complications and that this was achieved in males because of their generally lower HbF distribution. ${ }^{12}$ This concept was supported by proportional hazard analysis that indicated that for dactylitis, painful crises, and acute chest syndrome, there did appear to be a critical concentration of $\mathrm{HbF}$ below which the hazard was increased.

The significant relationship between painful crisis and $\mathrm{HbF}$ value may appear at variance with an earlier study that failed to show a relationship between $\mathrm{HbF}$ and painful crisis frequency in either sex. ${ }^{13}$ However, the end points of the two studies were different, the present study examining the age of onset of painful crises and the earlier study addressing painful crisis frequency. Both dactylitis and the painful crisis result from avascular necrosis of bone marrow and a similar behaviour to risk factors might have been anticipated. Avascular necrosis of bone marrow is likely to be influenced by both oxygen supply and demand of the expanded bone marrow. $\mathrm{HbF}$ concentration could influence supply by its effect on sickling and vaso-occlusion but could also influence demand if subjects with lower HbF concentrations had more rapid haemolysis and greater erythropoietic expansion.

Abdominal painful crisis and, to a lesser extent, hypersplenism appeared unrelated to $\mathrm{HbF}$ group. The pathology of the abdominal painful crisis remains unknown but the lack of a relationship with $\mathrm{HbF}$ suggests that this complication is not closely related to vasoocclusion. Low concentrations of $\mathrm{HbF}$ have been previously associated with the early appearance of splenomegaly ${ }^{5}$ and high concentrations of $\mathrm{HbF}$ influence the persistence of palpable splenomegaly. ${ }^{14}$ There was the suggestion of a trend between hypersplenism and $\mathrm{HbF}$ group in the present study but this failed to reach significance possibly because of the relatively small numbers of subjects with this complication.

The protective effect of $\mathrm{HbF}$ is believed to be twofold. High concentrations of $\mathrm{HbF}$ infer lower concentrations of sickle cell haemoglobin (HbS) within the cell but $\mathrm{HbF}$ molecules also participate less readily in $\mathrm{HbS}$ polymer formation. As a result there is an inverse relationship between $\mathrm{HbF}$ value and counts of irreversibly sickled cells. ${ }^{14}$ 15 The present study confirms that high and moderate concentrations of $\mathrm{HbF}$ determine a lower frequency and a later onset of the acute chest syndrome, dactylitis, painful crises, and acute splenic sequestration.

1 Serjeant GR. Fetal hemoglobin in homozygous sickle cell disease. Clinical Haematology 1975;4:109-22.

2 Perrine RP, Pembrey ME, John P, Perrine S, Shoup F Natural history of sickle cell anemia in Saudi Arabs. Ann Intern Med 1978;88:1-6.

$3 \mathrm{Kar}$ BC, Satapathy RK, Kulozik AE, et al. Sickle cell disease in Orissa State, India. Lancet 1986;i:1198-201.

4 Powars DR, Schroeder WA, Weiss JN, Chan LS, Azen SP. Lack of influence of fetal hemoglobin levels or erythrocyte Lack of influence of fetal hemoglobin levels or erythrocyte
indices on the severity of sickle cell anemia. $\mathcal{F}$ Clin Invest indices on the se
1980;65:732-45.

5 Stevens MCG, Hayes RJ, Vaidya S, Serjeant GR. Fetal hemoglobin and clinical severity of homozygous sickle cell disease in early childhood. $\mathcal{F}$ Pediatr 1981;98:37-41

6 Serieant BE, Forbes M, Williams LL, Serieant GR. Screening cord bloods for the detection of sickle cell disease in Jamaica. Clin Chem 1974;20:666.

7 Betke K, Marti HR, Schlicht I. Estimation of small percentage of foetal haemoglobin. Nature 1959;84:1877-8.

8 Topley JM, Rogers DW, Stevens MCG, Serieant GR. Acute splenic sequestration and hypersplenism in the first five years in homozygous sickle cells disease. Arch Dis Child 1981;56:765-9.

9 Aitkin M, Anderson D, Francis B, Hinde J. Statistical modelling in GLIM. Oxford: Clarendon Press, 1989.

10 Powars DR, Weiss JN, Chan LS, Schroeder WA. Is there a threshold level of fetal hemoglobin that ameliorates
morbidity in sickle cell anemia? Blood 1984;63:921-6.

11 Emond AM, Collis R, Darvill D, Maude GH, Serjeant GR. Acute splenic sequestration in homozygous sickle cell Acute splenic sequestration in homozygous sickle cell
disease; natural history and management. $\mathcal{F}$ Pediatr 1985 ; 107:201-6.

12 Mason KP, Grandison Y, Hayes RJ, et al. Post-natal decline of fetal haemoglobin in homozygous sickle cell disease: relationship to parental $\mathrm{HbF}$ levels. Brf Haematol 1982;52: 455-63.

13 Baum KF, Dunn DT, Maude GH, Serjeant GR. The painful crisis of homozygous sickle cell disease. A study of risk factors. Arch Intern Med 1987;147:1231-4.

14 Serjeant GR. Irreversibly sickled cells and splenomegaly in sickle-cell anaemia. Brf Haematol 1970;19:635-41.

15 Bertles JF, Milner PFA. Irreversibly sickled erythrocytes: a consequence of the heterogeneous distribution of hemoglobin types in sickle-cell anemia. $\mathcal{F}$ Clin Invest 1968;47: 1731-41. 